\title{
Long-term risk of renal and urinary tract diseases in childhood cancer survivors : A population-based cohort study
}

\section{Bonnesen, Trine Gade}

2016-09

Bonnesen , T G , Winther , J F , Asdahl , P H , Licht , S D F , Gudmundsdottir , T , Holmqvist , A S , Madanat-Harjuoja , L-M , Tryggvadottir , L , Wesenberg , F, Birn , H, Olsen , J H, Hasle , H \& ALiCCS Study Grp 2016 , ' Long-term risk of renal and urinary tract diseases in childhood cancer survivors : A population-based cohort study ' , European Journal of Cancer , vol. 64 , pp. 52-61. https://doi.org/10.1016/j.ejca.2016.05.006

http://hdl.handle.net/10138/224120

https://doi.org/10.1016/j.ejca.2016.05.006

publishedVersion

Downloaded from Helda, University of Helsinki institutional repository.

This is an electronic reprint of the original article.

This reprint may differ from the original in pagination and typographic detail.

Please cite the original version. 


\section{Long-term risk of renal and urinary tract diseases in childhood cancer survivors: A population-based cohort study}

Trine Gade Bonnesen ${ }^{\mathrm{a}, *}$, Jeanette F. Winther ${ }^{\mathrm{b}}$, Peter H. Asdahl ${ }^{\mathrm{a}}$, Sofie de Fine Licht ${ }^{\mathrm{b}}$, Thorgerdur Gudmundsdottir ${ }^{\mathrm{b}}$, Anna Sällfors Holmqvist ${ }^{c}$, Laura-Maria Madanat-Harjuoja d,e, Laufey Tryggvadottir f,g, Finn Wesenberg ${ }^{\mathrm{h}}$, Henrik Birn ${ }^{\mathrm{i}}$, Jørgen H. Olsen ${ }^{b}$, Henrik Hasle ${ }^{a}$ on behalf of the ALiCCS study group

\footnotetext{
a Department of Pediatrics, Aarhus University Hospital, Palle Juul-Jensens Boulevard 99, 8200 Aarhus N, Denmark

${ }^{\mathrm{b}}$ Danish Cancer Society Research Center, Strandboulevarden 49, 2100 Copenhagen, Denmark

${ }^{c}$ Pediatric Oncology and Hematology, Skane University Hospital, Department of Clinical Sciences, Lund University, Lund, Sweden

d Finnish Cancer Registry, Pieni Roobertinkatu 9, 00130 Helsinki, Finland

${ }^{\mathrm{e}}$ Department of Pediatrics, University of Helsinki and Helsinki University Hospital, Helsinki, Finland

${ }^{\mathrm{f}}$ Faculty of Medicine, Laeknagardur, University of Iceland, Reykjavik, Iceland

${ }^{\mathrm{g}}$ The Icelandic Cancer Registry, Skogarhlid 9, PO Box 5420, 125 Reykjavik, Iceland

${ }^{\text {h }}$ Cancer Registry of Norway, P.O. Box 5313, Majorstuen, Oslo, Norway

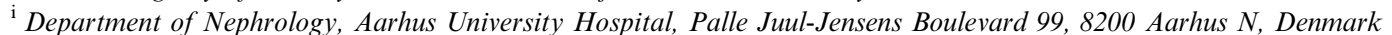

Received 8 February 2016; received in revised form 28 April 2016; accepted 4 May 2016

Available online 18 June 2016

\section{KEYWORDS}

Childhood cancer;

Survivorship;

Late complications;

Renal diseases;

Urinary tract diseases

\begin{abstract}
Background: Childhood cancer has been associated with long-term risk of urinary tract diseases, but risk patterns remain to be comprehensively investigated. We analysed the lifetime risk of urinary tract diseases in survivors of childhood cancer in the Nordic countries. Methods: We identified 32,519 one-year survivors of childhood cancer diagnosed since the 1940 s and 1950s in the five Nordic cancer registries and selected 211,156 population comparisons of a corresponding age, sex, and country of residence from the national population registries. To obtain information on all first-time hospitalizations for a urinary tract disease, we linked all study subjects to the national hospital registry of each country. Relative risks (RRs) and absolute excess risks (AERs) and associated 95\% confidence intervals (CIs) for urinary tract diseases among cancer survivors were calculated with the appropriate morbidity rates among comparisons as reference.
\end{abstract}

\footnotetext{
* Corresponding author.

E-mail address: bonnesen@dadlnet.dk (T.G. Bonnesen).
} 
Results: We observed 1645 childhood cancer survivors ever hospitalized for urinary tract disease yielding an RR of 2.5 (95\% CI 2.4-2.7) and an AER of 229 (95\% CI 210-248) per 100,000 person-years. The cumulative risk at age 60 was $22 \%$ in cancer survivors and $10 \%$ in comparisons. Infections of the urinary system and chronic kidney disease showed the highest excess risks, whereas survivors of neuroblastoma, hepatic and renal tumours experienced the highest RRs.

Conclusion: Survivors of childhood cancer had an excess risk of urinary tract diseases and for most diseases the risk remained elevated throughout life. The highest risks occurred following therapy of childhood abdominal tumours.

(c) 2016 Elsevier Ltd. All rights reserved.

\section{Introduction}

Remarkable improvements in therapy for paediatric malignancies have led to an increasing number of adults treated for cancer during childhood. In the Nordic countries, 5-year survival rates after childhood cancer now exceed $80 \%$ [1] and almost 1 in 1000 adults in the general population is a childhood cancer survivor [2]. However, a considerable number of survivors experience long-term therapy-related complications $[3,4]$. Only few and relatively small studies are available on the risk of diseases of the urinary tract following treatment for childhood cancer $[5,6]$. Important contributors to renal damage are nephrotoxic chemotherapy, nephrectomy, and abdominal irradiation [7]. The St. Jude Lifetime Cohort Study reported kidney dysfunction in $5 \%$ of adult cancer survivors [8]. The aim of this study was to identify urinary tract diseases through long-term follow-up in a large cohort of childhood cancer survivors in the five Nordic countries. To measure the relative and absolute risk of urinary tract morbidities we used diagnostic information available in the national hospital registers including risk estimates for individuals aged $>50$ years which have not previously been reported in cohort studies of childhood cancer survivors.

\section{Methods}

This study is part of a Nordic population-based cohort study, Adult Life after Childhood Cancer in Scandinavia (ALiCCS; www.aliccs.org) [9-11].

\subsection{Patient and comparison cohorts}

The basic childhood cancer cohort included 43,909 individuals diagnosed with cancer before the age of 20 years from start of registration in the 1940s and 1950s, until 31st December 2008 (eTable1). Patients had to be alive on or born after the date on which centralised registration of residents of each country was operational to be included. The Nordic cancer registries include nationwide data on incident cases of cancer reported from multiple sources ensuring close to full coverage [12-16]. We obtained information on type of cancer and date of diagnosis and assigned individuals to 1 of 12 main diagnostic groups according to the International Classification Scheme for Childhood Cancer [17].

All residents in the Nordic countries are assigned a unique personal identification number, which allows accurate linkage of information between registries and complete follow-up on vital status and emigration [18].

To measure hospitalization rates for urinary tract diseases in the background population, we randomly selected 219,131 comparison subjects from the population registries (eTable 1). For each childhood cancer patient, five comparisons were selected, who were alive on the date of cancer diagnosis of the corresponding patient, and were of the same sex, age, country of residence, and without a diagnosis of cancer before the age of 20 years. For 317 patients fewer than five comparisons were available (eFig. 1).

Patients, in whom more than one primary cancer was diagnosed before the age of 20 years, were excluded (305 patients). Furthermore, we excluded those who had died, emigrated, or were censored during the first year after the date of cancer diagnosis or an equivalent time lag for the comparisons (6844 patients; 1318 comparisons). We also excluded those who had died or emigrated before the start of the national hospital registries (3600 patients; 4858 comparisons).

In accordance with Nordic regulations, data on cohort members were analysed without personal identifiers. The study was approved by the national bioethics committees and national data protection authorities according to national regulations.

\subsection{Hospitalizations for urinary tract diseases}

Each hospitalization obtained from the national hospital registries initiated a record including the personal identification number of the patient, date of admission and discharge, a primary discharge diagnosis, and supplementary diagnoses coded according to the 
International Classification of Diseases (ICD-7 to ICD10) $[19-21]$.

We identified all inpatient hospitalizations with a primary or supplementary discharge diagnosis (ICD-10 codes N00-21 and N23-39; ICD-9 codes 580-599; ICD-8 codes 580-583 and 590-599; ICD-7 codes 590-594 and 600-604; for a detailed list of ICD-10 codes please see eTable 2). Diagnostic categories of ICD-7 to ICD-9 were adapted to the ICD-10. Linkage to the hospital registries identified 197 patients and 206 comparisons diagnosed with a congenital chromosomal abnormality (ICD-10 codes Q90-99, e.g. Turner syndrome, Down syndrome, and Klinefelter syndrome); they were excluded because these disorders may potentially confound causal associations between cancer treatment and urinary tract diseases. Finally, we excluded 444 survivors and 1530 comparisons, who had been hospitalized for a urinary tract disease prior to the date of childhood cancer diagnosis (or the equivalent date for comparisons), leaving a total of 32,519 one-year survivors and 211,156 comparisons for analysis (eTable 1, eFig. 1).

\section{Statistical analysis}

Follow-up in the hospital registries started 1 year after the date of cancer diagnosis (and the corresponding date for comparisons), or at the start of the national hospital registry, whichever occurred last. Follow-up ended on the date of death, the date of emigration, or end of the study period (eTable 1), whichever occurred first. Follow-up also ended if a second primary cancer was diagnosed in a survivor or a first primary cancer in a population comparison. Only the first hospitalization for a specific urinary tract disease was retained, as it was presumed to correspond to the date of diagnosis. Risk analyses were carried out for each of the eight main diagnostic categories, and for each of the 35 subcategories within the main categories (Table 2) including risk estimates for subcategories based on five or more hospitalizations among survivors. The observed numbers of first hospitalizations for a given urinary tract disease among survivors were compared with the expected numbers derived from the appropriate country-, sex-, age-, and calendar period-specific hospitalization rates of the population comparisons. We estimated the significance and $95 \%$ confidence intervals (CIs) for the standardized hospitalization rate ratio, taken as the observed-to-expected hospitalizations using Fieller's theorem [22]. Absolute excess risk (AER), i.e. the additional risk for a hospitalization, was derived as the difference between the observed and expected first hospitalization rates per 100,000 person-years, with corresponding $95 \%$ CI. To test the robustness of the overall results, we added three sensitivity analyses. First, an analysis with inclusion of urinary tract diseases only notified as a primary diagnosis. Second, an analysis
Table 1

Characteristics for the 32,519 one-year survivors of childhood cancer in the Nordic countries followed for diseases of the urinary tract.

\begin{tabular}{|c|c|c|}
\hline & $\mathrm{N}(\%)$ & $\begin{array}{l}\text { Person-years } \\
\text { of follow-up }\end{array}$ \\
\hline Total & $32,519(100)$ & 430,614 \\
\hline \multicolumn{3}{|l|}{ Sex } \\
\hline Female & $15,101(46.4)$ & 206,668 \\
\hline Male & $17,418(53.6)$ & 224,946 \\
\hline \multicolumn{3}{|l|}{ Country } \\
\hline Denmark & $7422(23)$ & 115,158 \\
\hline Finland & $7090(22)$ & 101,370 \\
\hline Iceland & $409(1)$ & 3125 \\
\hline Norway & $5269(16)$ & 15,191 \\
\hline Sweden & $12,329(38)$ & 195,770 \\
\hline \multicolumn{3}{|l|}{ Cancer diagnosis } \\
\hline I. Leukaemia & $6843(21)$ & 70,384 \\
\hline II. Lymphomas & 4442 (14) & 59,137 \\
\hline $\begin{array}{l}\text { III. Central nervous system } \\
\text { tumours }\end{array}$ & $7834(24)$ & 107,295 \\
\hline IV. Neuroblastoma & $1290(4)$ & 15,887 \\
\hline V. Retinoblastoma & $818(3)$ & 15,831 \\
\hline VI. Renal tumours & $1367(4)$ & 21,577 \\
\hline VII. Hepatic tumours & $235(1)$ & 2018 \\
\hline VIII. Malignant bone tumours & $1519(5)$ & 18,014 \\
\hline IX. Soft-tissue sarcomas & $1962(6)$ & 27,397 \\
\hline X. Germ-cell tumours & $2097(6)$ & 28,420 \\
\hline XI. Malignant epithelial tumours & $3646(11)$ & 58,972 \\
\hline $\begin{array}{l}\text { XII. Other and unspecified } \\
\text { malignant neoplasms }\end{array}$ & $466(1)$ & 5682 \\
\hline \multicolumn{3}{|l|}{ Age at diagnosis } \\
\hline$<4$ years & $9890(30)$ & 131,811 \\
\hline $5-9$ years & $5746(18)$ & 74,606 \\
\hline $10-14$ years & $6374(20)$ & 85,451 \\
\hline $15-19$ years & $10,509(32)$ & 138,746 \\
\hline \multicolumn{3}{|l|}{ Calendar time at diagnosis } \\
\hline $1943-1959$ & $1047(3)$ & 26,718 \\
\hline 1960-1974 & $4526(14)$ & 107,234 \\
\hline $1975-1989$ & $10,006(31)$ & 170,941 \\
\hline $1990-2008$ & $16,940(52)$ & 125,721 \\
\hline
\end{tabular}

restricted to include 5-year survivors only. Third, an analysis restricted to survivors diagnosed with cancer from 1 year before the start of the national patient registries to the end of the study period.

To estimate the effects of cancer type and age at diagnosis on the risk for urinary tract diseases, we conducted a multivariate analysis within the survivor cohort. A Cox proportional hazards model was used to estimate hospitalization rate (hazard) ratios (HRs) for urinary tract disease for type of childhood cancer (12 diagnostic groups with leukaemia survivors as reference) and for age at diagnosis (four groups with $0-4$ years as reference) with time since diagnosis as the underlying time scale and censoring for death. The analysis was stratified by sex and country. The analysis was adjusted for age at diagnosis in 5-year age group interval and year of diagnosis in four calendar year groups $(<1980$, 1980-1989, 1990-1999, >2000). The statistical software $\mathrm{R}$ version 2.12.0 and packages Survival and Design were used for these analyses.

For all other analyses we used SAS version 9.2. 
Table 2

The observed and expected numbers of first-time hospitalization for diseases of the urinary tract among 32,519 one-year survivors of childhood cancer and 211,156 population comparisons by eight main categories and 35 subcategories and diagnoses.

\begin{tabular}{|c|c|c|c|c|c|}
\hline \multirow[t]{2}{*}{ Renal and urinary tract disease } & \multirow[t]{2}{*}{ ICD-10 code } & \multicolumn{2}{|c|}{ First hospital contacts (n) } & \multirow[t]{2}{*}{ RR $(95 \% \mathrm{CI})$} & \multirow[t]{2}{*}{ AER $(95 \% \text { CI })^{b}$} \\
\hline & & Observed $^{\mathrm{a}}$ & Expected $^{\mathrm{a}}$ & & \\
\hline Any renal and urinary tract disease & & 1645 & 657.4 & $2.5(2.4-2.7)$ & $229(210-248)$ \\
\hline Glomerular diseases & & 124 & 60.6 & $2.0(1.7-2.5)$ & $15(9-20)$ \\
\hline Acute nephritis & N00.0-N01.9 & 19 & 13.0 & $1.5(0.9-2.4)$ & $1(-1$ to 4$)$ \\
\hline Haematuria with glomerular pathology & N02.0-8 & 25 & 9.8 & $2.6(1.6-4.0)$ & $4(1-6)$ \\
\hline Chronic nephritis & N03.0-9 & 27 & 11.8 & $2.3(1.5-3.5)$ & $4(1-6)$ \\
\hline Nephrotic syndrome & N04.0-9 & 25 & 10.2 & $2.5(1.6-3.9)$ & $3(1-6)$ \\
\hline Nephritis, unspecified & N05.0-9 & 16 & 8.2 & $2.0(1.1-3.4)$ & $2(0-4)$ \\
\hline Glomerular disorders in diseases classified elsewhere & N08.0-9 & 18 & 7.0 & $2.6(1.5-4.4)$ & $3(1-5)$ \\
\hline Renal tubulo-interstitial diseases & & 33 & 4.6 & $7.1(4.5-11.4)$ & $8(5-11)$ \\
\hline $\begin{array}{l}\text { Drug- and heavy-metal-induced tubulo-interstitial } \\
\text { and tubular conditions }\end{array}$ & N14.0-9 & 17 & 1.1 & $15.6(6.8-35)$ & $5(2-7)$ \\
\hline $\begin{array}{l}\text { Disorders resulting from impaired renal tubular } \\
\text { function }\end{array}$ & N25.8-9 & 11 & 1.9 & $5.8(2.7-12.7)$ & $3(1-5)$ \\
\hline Acute renal failure (excluding glomerular disorders) & & 120 & 17.1 & $7.0(5.5-9.0)$ & $24(19-29)$ \\
\hline Acute renal failure & N17.0-9 & 117 & 15.7 & $7.5(5.8-9.6)$ & $24(19-29)$ \\
\hline $\begin{array}{l}\text { Chronic kidney disease (excluding glomerular } \\
\text { disorders) }\end{array}$ & & 264 & 72.1 & $3.7(3.2-4.2)$ & $45(37-52)$ \\
\hline Chronic pyelonephritis & N11.8-9 & 28 & 3.6 & $7.8(4.6-13.1)$ & $6(3-8)$ \\
\hline Other pyelonephritis, pyelitis and pyelocystitis & N18.0-9 & 69 & 25.5 & $2.7(2.1-3.6)$ & $10(6-14)$ \\
\hline Chronic renal failure & N19.0-9 & 116 & 21.6 & $5.4(4.2-6.8)$ & $22(17-27)$ \\
\hline Renal failure, unspecified & N19.0-9 & 38 & 8.5 & $4.5(3.0-6.6)$ & $7(4-10)$ \\
\hline Hypertensive renal disease with renal failure & $\mathrm{I} 12.0$ & 23 & 4.1 & $5.7(3.3-9.7)$ & $4(2-7)$ \\
\hline Diabetes mellitus with renal complications & $\begin{array}{l}\mathrm{E} 10.2, \mathrm{E} 11.2, \\
\mathrm{E} 12.2, \mathrm{E} 13.2, \mathrm{E} 14.2\end{array}$ & 26 & 13.6 & $1.9(1.1-2.9)$ & $3(0-5)$ \\
\hline Cystis renis asqusitas & $\mathrm{N} 28.1$ & 6 & 1.9 & $3.2(1.2-8.1)$ & $1(0-2)$ \\
\hline Urolithiasis & & 234 & 134.5 & $1.7(1.5-2.0)$ & $23(16-30)$ \\
\hline Calculus of kidney and ureter & $\mathrm{N} 20.0-9$ & 211 & 126.0 & $1.7(1.1-1.9)$ & $20(13-27)$ \\
\hline Calculus of other parts of urinary system & $\mathrm{N} 21.0-9$ & 24 & 10.2 & $2.4(1.5-3.7)$ & $3(1-6)$ \\
\hline Obstructive uropathy & & 149 & 60.5 & $2.5(2.1-3.0)$ & $21(15-26)$ \\
\hline $\begin{array}{l}\text { Pyelonephritis chronica } \mathrm{m} / \text { vesicourethral reflux or } \\
\text { obstruction }\end{array}$ & N11.0-1 & 6 & 1.6 & $3.8(1.4-10.1)$ & $1(0-2)$ \\
\hline Hydronephrosis & N13.0-3 & 79 & 31.1 & $2.6(2.0-3.4)$ & $11(7-16)$ \\
\hline $\begin{array}{l}\text { Kinking and stricture of ureter without } \\
\text { hydronephrosis }\end{array}$ & N13.5 & 9 & 2.6 & $3.5(1.6-7.6)$ & $1.5(0.1-2.9)$ \\
\hline Obstruction of ureter, not elsewhere classified & N13.8-9 & 14 & 5.8 & $2.4(1.3-4.4)$ & $1.9(0.2-2.9)$ \\
\hline Bladder-neck obstruction & N32.0 & 8 & 3.1 & $2.6(1.2-5.7)$ & $1(0-3)$ \\
\hline Stricture of urethra & N35.0-9 & 42 & 19.6 & $2.1(1.5-3.0)$ & $5(2-8)$ \\
\hline Infections of the urinary system & & 830 & 302.3 & $2.8(2.5-3.0)$ & $123(109-136)$ \\
\hline Acute pyelonephritis & N10.0-9 & 151 & 68.1 & $2.2(1.9-2.7)$ & $19(14-25)$ \\
\hline Pyonephrosis & N13.6 & 5 & 1.9 & $2.6(1.0-7.2)$ & $1(0-2)$ \\
\hline Cystitis & $\mathrm{N} 30.0-9$ & 306 & 110.0 & $2.8(2.4-3.2)$ & $46(38-54)$ \\
\hline Urethritis (non-venereal) & $\mathrm{N} 34.0-9, \mathrm{~N} 37.0$ & 18 & 9.9 & $1.8(1.1-3.0)$ & $1.9(-0.1$ to 3.9$)$ \\
\hline Urinary tract infection site not specified & N39.0 & 373 & 98.2 & $3.8(3.4-4.3)$ & $64(55-73)$ \\
\hline Other and unspecified disorders & & 315 & 106.2 & $3.0(2.6-3.4)$ & $48(40-57)$ \\
\hline Other disorders of kidney and ureter & $\begin{array}{l}\text { N23.0-9, N28.8-9, } \\
\text { N29.8, N13.7 }\end{array}$ & 52 & 18.5 & $2.8(2.1-3.9)$ & $8(4-11)$ \\
\hline Proteinuria, not specified & N06.9, N39.1 & 7 & 1.5 & $4.8(1.9-12.4)$ & $1(0-3)$ \\
\hline $\begin{array}{l}\text { Neuromuscular dysfunction of bladder, not } \\
\text { elsewhere classified }\end{array}$ & N31.0-9 & 123 & 11.0 & $11.1(8.5-14.7)$ & $26(21-31)$ \\
\hline Others disorders of bladder & $\mathrm{N} 32.1-9, \mathrm{~N} 33.8$ & 68 & 11.1 & $6.1(4.5-8.4)$ & $13(9-17)$ \\
\hline Incontinence & $\mathrm{N} 39.3-4$ & 73 & 53.8 & $1.4(1.1-1.7)$ & $4(0-9)$ \\
\hline Other disorders of urinary tract & N39.8-9 & 30 & 11.0 & $2.7(1.8-4.1)$ & $4.4(1.9-7.0)$ \\
\hline
\end{tabular}

CI, confidence interval.

Standardized hospitalization rate ratio (RR) and absolute excess risk (AER) per 100,000 person-years are presented. For a detailed list of International Classification of Diseases, Tenth Revision (ICD-10) codes please see eTable2.

${ }^{\text {a }}$ The sum of observed and expected cases in subcategories does not correspond to the total number of cases observed and expected due to this report including risk estimates for subcategories based on five or more hospitalizations among cancer survivors

${ }^{b}$ The sum of AER in subcategories might not correspond to the sum of AER of diseases within these subcategories because individuals can have a first hospitalization for several diseases 


\section{Results}

The 32,519 one-year survivors were followed in the national hospital registries for 430,614 person-years, median 10 years; range $0-42$ years. Table 1 provides characteristics of the survivor cohort.

\subsection{Overall risk for diseases of the urinary tract}

Fig. 1 shows the relative risk (RR) of hospitalization for any urinary tract disease in all survivors combined and in survivors stratified by sex, age at cancer diagnosis, main diagnostic category of childhood cancer, and time since cancer diagnosis. A total of 1645 survivors had been hospitalized for a urinary tract disease, when 657 were expected, yielding an increased risk of 2.5 and an AER of 229 cases per 100,000 person-years (Fig. 1; Table 2).

The repeated analysis restricted to include only urinary tract diseases reported as the primary discharge diagnosis resulted in a lower risk of 2.0 (95\% CI $1.8-2.2)$. The analysis restricted to include only 5 -year survivors resulted in a lower risk of $2.2(95 \%$ CI 2.1-2.4), whereas the analysis restricted to include survivors diagnosed with cancer 1 year before the start of the national patient registries and onwards resulted in a higher risk of $2.9(95 \%$ CI 2.7-3.2).

\subsection{Risk of specified diagnostic categories of urinary tract diseases}

Survivors were at significantly increased risk of being hospitalized for urinary tract diseases of all eight main diagnostic categories (Table 2). Infections of the urinary system were the most common diagnosis with 830 hospitalizations and an AER of 123 cases per 100,000 person-years. The highest RRs were observed for druginduced tubulo-interstitial and tubular disorders (RR 15.6) and neuromuscular dysfunction of the bladder (11.1).

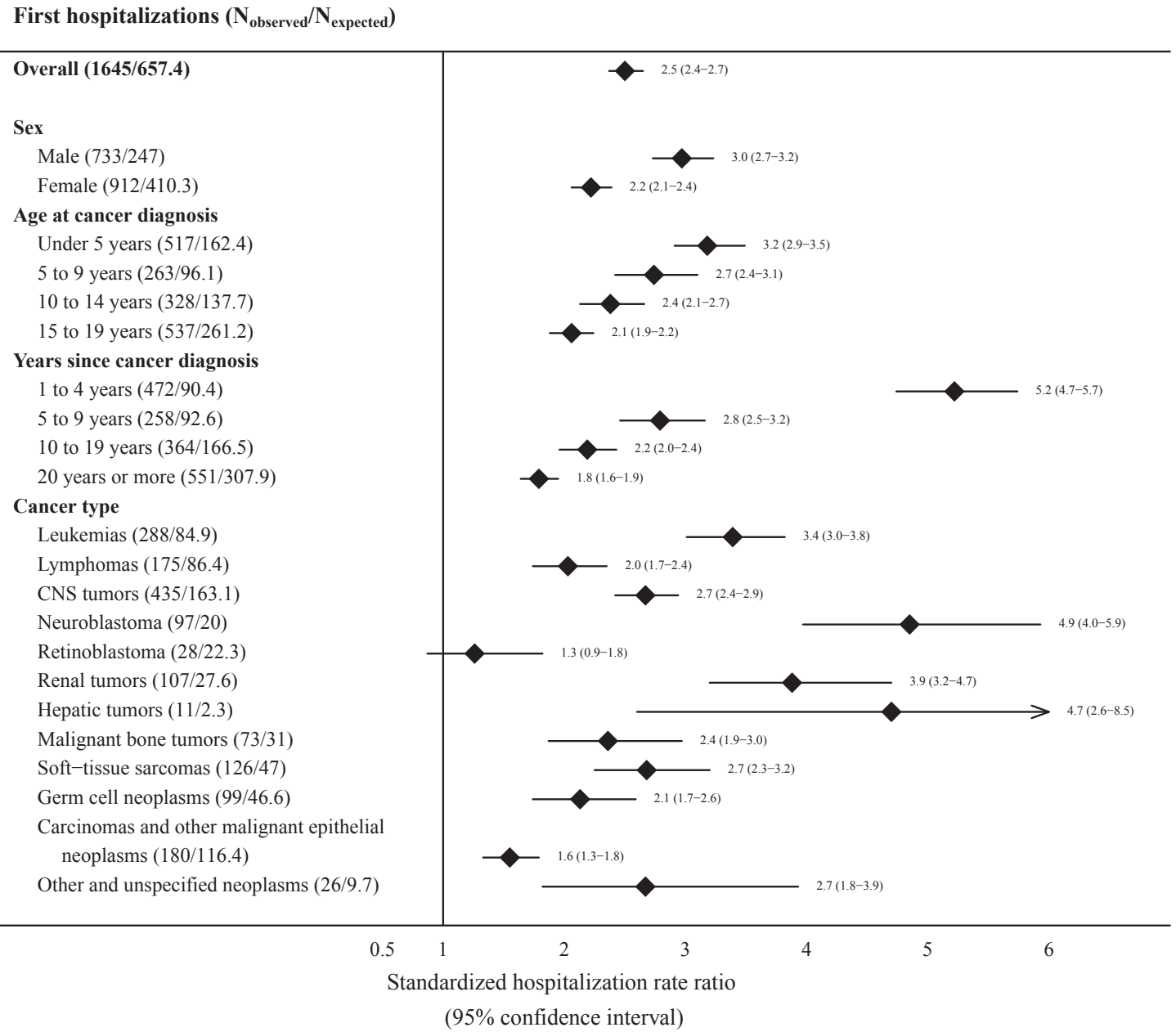

Fig. 1. Standardized hospitalization rate ratios for diseases of the urinary tract of any type among 32,519 one-year survivors. $N_{\text {observed }}$ is the number of first hospitalizations among cancer survivors. $N_{\text {expected }}$ is the number of hospitalizations expected based upon morbidity rates derived from the comparison cohort. 
Table 3

Standardized hospitalization rate ratio (RR) and absolute excess risk (AER) per 100,000 person-years for urinary tract disease of any type by the 12 main diagnostic groups of cancer.

\begin{tabular}{|c|c|c|c|}
\hline & $\begin{array}{l}\text { First hospital contacts } \\
\text { in survivors }(\mathrm{n})\end{array}$ & RR $(95 \%$ CI $)$ & $\begin{array}{l}\text { AER }(95 \% \text { CI }) \\
\text { per } 100,000 \text { person-years }\end{array}$ \\
\hline \multicolumn{4}{|l|}{ Leukaemia $(n=6843)$} \\
\hline Any renal or urinary tract disease & 288 & $3.4(3.0-3.8)$ & $289(241-336)$ \\
\hline Acute renal failure & 25 & $17(11-26)$ & $33(19-47)$ \\
\hline Renal tubulo-interstitial diseases & 4 & $7.9(2.7-23)$ & $5(-0.6$ to 11$)$ \\
\hline Chronic kidney disease & 28 & $3.9(2.6-5.7)$ & $29(15-44)$ \\
\hline Urolithiasis & 44 & $3.6(2.7-4.9)$ & $45(27-64)$ \\
\hline Infections of the urinary system & 159 & $3.5(3.0-4.1)$ & $161(126-196)$ \\
\hline \multicolumn{4}{|l|}{ Lymphomas $(n=4442)$} \\
\hline Any renal or urinary tract disease & 175 & $2.0(1.7-2.4)$ & $150(106-194)$ \\
\hline Acute renal failure & 17 & $6.8(4.1-11)$ & $24(11-38)$ \\
\hline \multicolumn{4}{|c|}{ Central nervous system tumours $(n=7834)$} \\
\hline Any renal or urinary tract disease & 435 & $2.7(2.4-2.9)$ & $253(215-292)$ \\
\hline Other and unspecified disorders & 117 & $4.6(3.8-5.6)$ & $85(66-105)$ \\
\hline Acute renal failure & 20 & $4.6(2.9-7.3)$ & $15(6-23)$ \\
\hline Infections of the urinary system & 247 & $3.4(2.9-3.8)$ & $162(133-190)$ \\
\hline \multicolumn{4}{|l|}{ Neuroblastoma $(n=1290)$} \\
\hline Any renal or urinary tract disease & 97 & $4.9(4.0-5.9)$ & $485(363-606)$ \\
\hline Acute renal failure & 7 & $22(10-48)$ & $42(9-75)$ \\
\hline Other and unspecified disorders & 32 & $11(7.6-16)$ & $183(113-253)$ \\
\hline Chronic kidney disease & 19 & $10(6.1-15)$ & $107(53-161)$ \\
\hline Obstructive uropathy & 12 & $7.5(4.2-13.4)$ & $66(23-108)$ \\
\hline Glomerular diseases & 12 & $5.5(3.1-9.8)$ & $62(19-105)$ \\
\hline Infections of the urinary system & 48 & $4.7(3.5-6.2)$ & $238(152-323)$ \\
\hline \multicolumn{4}{|l|}{ Retinoblastoma $(\mathrm{n}=\mathbf{8 1 8})$} \\
\hline Any renal or urinary tract disease & 28 & $1.3(0.9-1.8)$ & $36(-29$ to 102$)$ \\
\hline \multicolumn{4}{|l|}{ Renal tumours $(n=1367)$} \\
\hline Any renal or urinary tract disease & 107 & $3.9(3.2-4.7)$ & $368(274-462)$ \\
\hline Renal tubulo-interstitial diseases & 4 & $22(8-63)$ & $18(-0.5$ to 36$)$ \\
\hline Acute renal failure & 11 & $21(11-38)$ & $48(18-79)$ \\
\hline Chronic kidney disease & 35 & $13(9-18)$ & $149(95-203)$ \\
\hline Obstructive uropathy & 13 & $5.4(3.1-9.4)$ & $49(16-82)$ \\
\hline Infections of the urinary system & 46 & $3.4(2.6-4.6)$ & $151(89-212)$ \\
\hline \multicolumn{4}{|l|}{ Hepatic tumours $(n=235)$} \\
\hline Any renal or urinary tract disease & 11 & $4.7(2.6-8.5)$ & $429(107-751)$ \\
\hline Renal tubulo-interstitial diseases & 1 & $100(13-752)$ & $49(-48$ to 146$)$ \\
\hline Acute renal failure & 3 & $71(23-226)$ & $147(-22$ to 315$)$ \\
\hline Chronic kidney disease & 2 & $12(3.0-48)$ & $91(-47$ to 228$)$ \\
\hline Obstructive uropathy & 2 & $10.3(2.6-41)$ & $89(-48$ to 227$)$ \\
\hline \multicolumn{4}{|l|}{ Malignant bone tumours $(n=1519)$} \\
\hline Any renal or urinary tract disease & 73 & $2.4(1.9-3.0)$ & $233(140-326)$ \\
\hline Renal tubulo-interstitial diseases & 4 & $17(6.3-49)$ & $21(-0.8$ to 43$)$ \\
\hline Chronic kidney disease & 17 & $4.5(2.8-7.3)$ & $73(28-118)$ \\
\hline \multicolumn{4}{|l|}{ Soft tissue sarcomas $(n=1962)$} \\
\hline Any renal or urinary tract disease & 126 & $2.7(2.3-3.2)$ & $288(208-369)$ \\
\hline Renal tubulo-interstitial diseases & 6 & $17(7.4-41)$ & $21(3-38)$ \\
\hline Acute renal failure & 10 & $6.4(3.4-12.2)$ & $31(8-53)$ \\
\hline Obstructive uropathy & 23 & $4.9(3.2-7.5)$ & $5(-17$ to 26$)$ \\
\hline \multicolumn{4}{|l|}{ Germ cell neoplasms $(n=2097)$} \\
\hline Any renal or urinary tract disease & 99 & $2.1(1.7-2.6)$ & $185(116-253)$ \\
\hline Chronic kidney disease & 21 & $4.1(2.7-6.3)$ & $19(3-36)$ \\
\hline \multicolumn{4}{|c|}{ Carcinomas and other malignant epithelial neoplasms $(n=3646)$} \\
\hline Any renal or urinary tract disease & 180 & $1.6(1.3-1.8)$ & $108(62-153)$ \\
\hline \multicolumn{4}{|c|}{ Other and unspecified neoplasms $(n=466)$} \\
\hline Any renal or urinary tract disease & 26 & $2.7(1.8-3.9)$ & $286(110-462)$ \\
\hline Renal tubulo-interstitial diseases & 1 & $20(2.8-148)$ & $17(-18$ to 51$)$ \\
\hline Acute renal failure & 3 & $9.6(3.1-30)$ & $47(-12$ to 107$)$ \\
\hline
\end{tabular}

CI, confidence interval.

Subcategories of urinary tract diseases with a lower $95 \%$ confidence limit of the RR of $\geq 2.5$ were included of each cancer diagnosis with the corresponding AER. 
Table 3 provides AER and RRs for a set of combinations of childhood cancer and urinary tract diseases for which the lower $95 \%$ confidence limit of RR was $\geq 2.5$. Apart from survivors of retinoblastoma, an increased risk of urinary tract disease in all categories of childhood cancer was identified. Among survivors of neuroblastoma, renal tumours, and leukaemia the risk for acute renal failure was particularly high; similarly the risk for chronic kidney disease was high in survivors of neuroblastoma, renal tumour and hepatic tumour.

Fig. 2 illustrates the observed and expected agespecific hospitalization rates among survivors and comparisons by time since diagnosis for any type of urinary tract disease and for a set of well-defined disease entities. Risk estimates varied considerably by time since diagnosis; the highest absolute risk for being hospitalized for urolithiasis was during the first 9 years after diagnosis; subsequently, the excess risk remained stable with an AER of almost 20 per 100,000 person-years.

Using the urinary tract morbidity in survivors of leukaemia as the standard, the within cohort analysis showed that the risk of being hospitalized for any disease was highest in survivors of neuroblastoma and renal tumours (Table 4). Survivors diagnosed in the age group 15-19 years had the highest risk for a urinary tract disease compared to those diagnosed at younger age, particularly prominent in survivors of leukaemia.
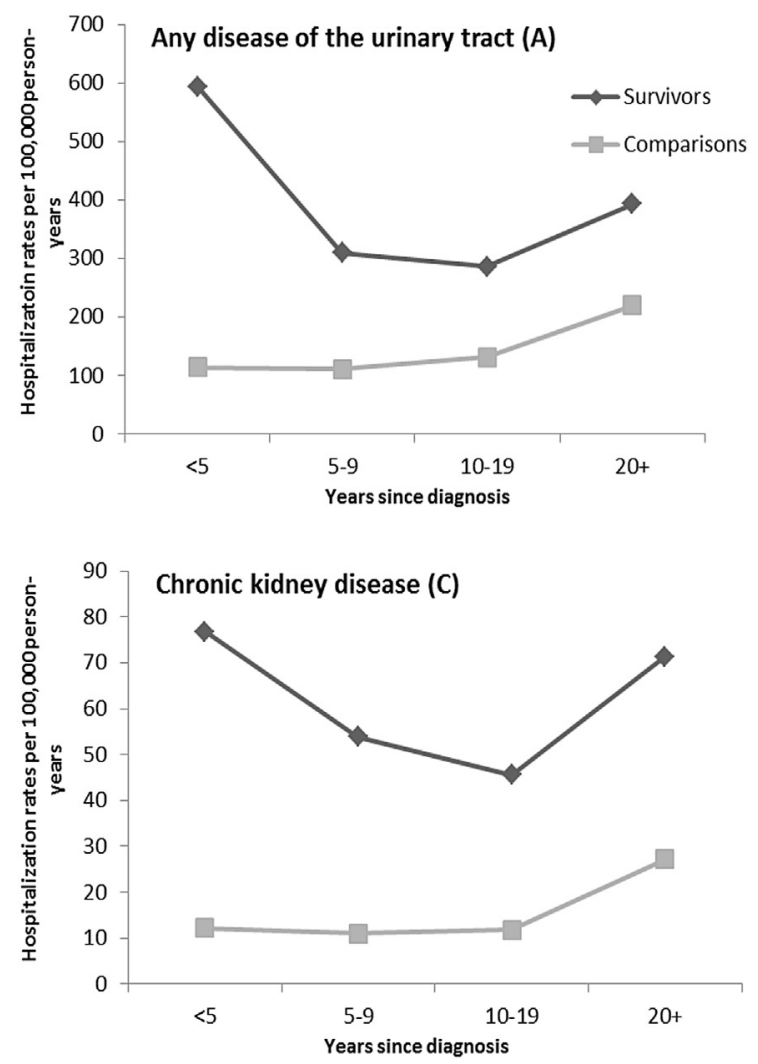

\section{Discussion}

Our study of 32,519 one-year childhood cancer survivors showed a 2.5 -fold increased risk of being hospitalized for a urinary tract disease compared with the general population. Particularly high risks were noted for survivors of neuroblastoma, renal tumours, and leukaemia. The study showed that the excess risk of urinary tract diseases remains high for $>20$ years after cancer diagnosis.

The aim was to give a comprehensive overview of the risks of various urinary tract diseases among childhood cancer survivors. With the population-based design and complete follow-up of cancer survivors, we were able to eliminate the risk of selection bias.

Most prior studies investigating long-term effects from treatment of childhood cancer were based on selfreported disease outcomes [23]. In the US Childhood Cancer Survivor Study (CCSS), comprising nearly 14,000 five-year survivors and 3900 sibling comparisons, survivors were almost nine times more likely than siblings to report renal failure or dialysis [3]. In our Nordic study, we observed a sevenfold increased risk for acute renal failure and an almost fourfold increased risk for chronic kidney disease among cancer survivors compared with the general population. Acute renal failure was diagnosed in 120 survivors and the risk was
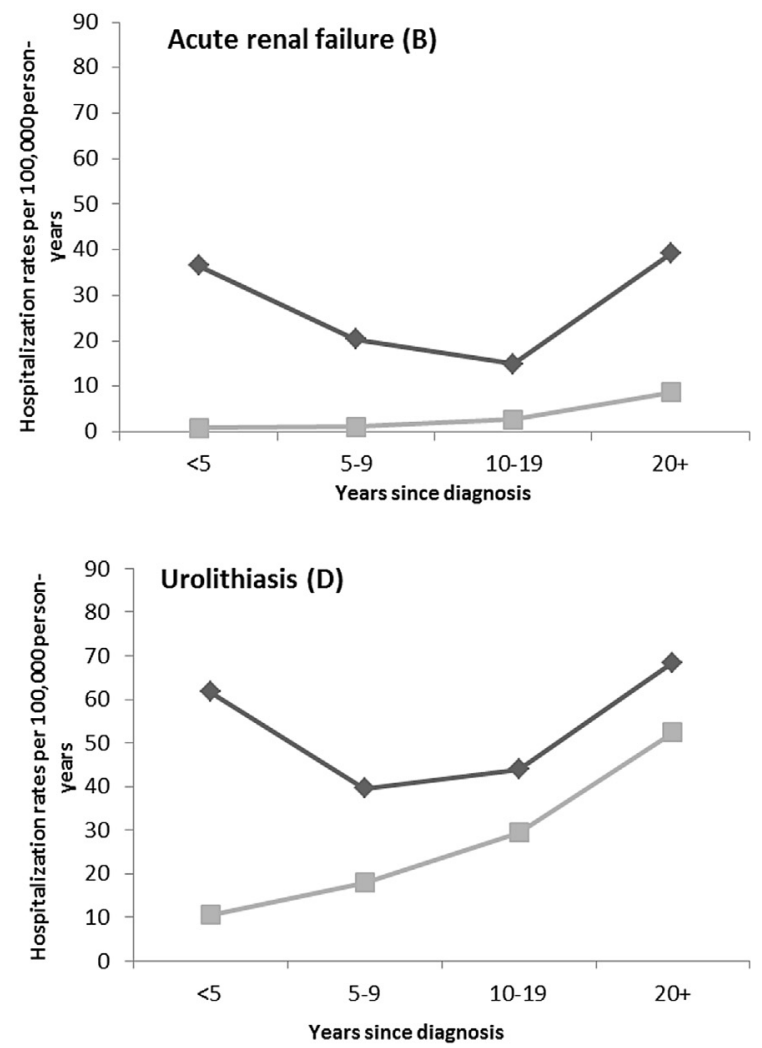

Fig. 2. Observed and expected hospitalizations rates per 100,000 person-years by years since cancer diagnosis for any disease of the urinary tract and for three specific diagnoses. (A) any disease of the urinary tract, (B) acute renal failure, (C) chronic kidney disease, (D) urolithiasis. 
Table 4

Within cohort Cox analysis with hazard ratios (HRs) and 95\% confidence intervals (CIs) for the risk of hospitalization for any disease of the urinary tract according to type of cancer.

\begin{tabular}{ll}
\hline Cancer diagnosis & $\begin{array}{l}\text { The risk of hospitalization for } \\
\text { any disease of the urinary tract }\end{array}$ \\
\cline { 2 - 2 } & HR $(95 \%$ CI $)$ \\
\hline Leukaemia & 1.0 \\
Lymphomas & $0.71(0.58-0.87)$ \\
Central nervous system tumours & $1.00(0.85-1.17)$ \\
Neuroblastoma & $1.61(1.28-2.04)$ \\
Retinoblastoma & $0.47(0.32-0.70)$ \\
Renal tumours & $1.36(1.08-1.70)$ \\
Hepatic tumours & $1.29(0.70-2.35)$ \\
Malignant bone tumours & $0.93(0.71-1.22)$ \\
Soft tissue sarcomas & $1.12(0.91-1.39)$ \\
Germ cell neoplasms & $0.79(0.62-1.01)$ \\
Carcinomas and other malignant & $0.66(0.54-0.82)$ \\
$\quad$ epithelial neoplasms & \\
Other and unspecified neoplasms & $1.01(0.67-1.51)$ \\
Age at time of cancer diagnosis & \\
$0-4$ years & 1.00 \\
5-9 years & $1.00(0.85-1.16)$ \\
10-14 years & $1.12(0.97-1.30)$ \\
15-19 years & $1.24(1.07-1.44)$ \\
Leukaemia & \\
Age at cancer diagnosis & \\
0-4 years & 1.0 \\
5-9 years & $1.33(0.98-1.80)$ \\
10-14 years & $1.91(1.40-2.60)$ \\
15-19 years & $2.39(1.66-3.43)$ \\
\hline
\end{tabular}

HR is presented according to age at time of cancer diagnosis for the entire cohort and for patients with leukaemia alone.

elevated more than 20 years after cancer diagnosis. The high risk of acute renal failure is only partly explained by an underlying chronic kidney disease as only 27 of the 120 survivors had been previously hospitalized for this condition. Some of these late cases might be explained by kidney damage presenting later in life, or the coexistence of congestive heart failure, diabetes mellitus, and/or hypertension [24-26]. Survivors of leukaemia, neuroblastoma, and renal tumours had a notably higher risk of acute renal failure compared with survivors of other cancer types. During treatment, patients with cancer commonly experience infectious events treated with nephrotoxic antibiotics such as aminoglycosides and vancomycin. Acute renal injury has been reported in children treated with vancomycin with risks further increased after concomitant use of nephrotoxic chemotherapeutic agents [27,28]. The substantial increase seen among leukaemia survivors in our study could be explained by the generally extended treatment periods with need of antibiotics and/or by treatment with high-dose methotrexate [6,29-31]. In our cohort, 116 survivors were hospitalized for chronic renal failure during follow-up equivalent to $0.36 \%$ of all survivors. This estimate is compatible with the $0.3 \%$ of the 5 -year survivors reporting chronic renal failure in the CCSS [32].
Some studies have suggested young age at cancer diagnosis to be an independent risk factor for developing a chronic kidney disease [5,33,34], whereas others have not been able to confirm this $[35,36]$. In our study chronic kidney disease was primarily reported among survivors of renal tumours, neuroblastoma, and leukaemia and in the unadjusted analysis the RR was highest among survivors diagnosed with cancer below the age of 5 years (data not shown); this is the age group where the vast majority of patients with Wilms tumour, neuroblastoma, and leukaemia are diagnosed. A within cohort analysis showed that the risk of being hospitalization for a urinary tract disease was highest in survivors of neuroblastoma and renal tumours and young age at time of cancer diagnosis was not an independent risk factor with the highest adjusted risk observed in those diagnosed with cancer between the age of 15 and 19 years. The highest risk was reported in survivors of leukaemia diagnosed in their late teens which correlates with both acute toxicity and dialysis occurring more frequently in adolescent patients with leukaemia than in younger patients [37].

Based on 44 observed cases, hospitalization for urolithiasis among leukaemia survivors was four times more common compared with the general population and occurred with an excess risk of 4.5 per 10,000 personyears. A study from St. Jude Children's Research Hospital comprising 2095 acute lymphoblastic leukaemia patients reported an incidence for urolithiasis of 1.8 per 10,000 person-years; however, this study was based on three cases only [38]. The relatively high number of survivors with urolithiasis in our study may be explained by increasingly more patients treated with haematopoietic stem cell transplantation and total body irradiation since the beginning of the 1980s [39].

Our study is limited by insufficient or absent information on treatment of the individual patient as this is not available in the cancer registries. Our results might be influenced by better medical surveillance of survivors than of comparisons, leading to potential overestimation of the relative and absolute risks for urinary tract diseases among survivors. We do not anticipate this will affect the more severe diseases such as acute renal failure and chronic kidney disease. Furthermore, the date of first admission is not always the day of the first diagnosis since some diagnoses are made in primary care or in an outpatient clinic before being hospitalized. However, we consider the first day of hospitalization as a reasonable surrogate marker for the date of diagnosis.

In conclusion, this large Nordic population-based study providing a comprehensive overview of diseases of the urinary tract among childhood cancer survivors showed that survivors had a substantially increased risk for virtually all diseases within the urinary tract and for most diseases this risk remained elevated throughout life. 


\section{Funding}

This work was supported by the Danish Council for Strategic Research (grant number 09-066899).

\section{Conflict of interest statement}

H.B. receives personal fees and other from Otsuka, grants from GlaxoSmithKline (GSK), personal fees from Alexion, AstraZeneca, and Novartis, outside the submitted work. The other authors declare no conflicts of interest.

\section{Author's contributions}

TGB is the principal investigator. She has contributed in the design, literature search, data analyses and interpretation. She has written all draft and final version of the report and created all tables and figures.

$\mathrm{JHO}, \mathrm{JFW}$, and $\mathrm{HH}$ contributed to the conception and design.

JHO, SDFL, TG, LT, ASH, LMMH, and FW contributed to the collection and assembly of data.

JHO, JFW, PHA, SDFL, TG, HB, and $\mathrm{HH}$ contributed to the data analyses and interpretation.

All authors contributed to preparation of the report and approved the final version.

\section{Ethics committee approval}

In accordance with Nordic regulations, data on cohort members were analysed without personal identifiers. The study was approved by the national bioethics committees and national data protection authorities according to national regulations (Denmark: 2010-414334, Finland: THL/1284/5.05.00/2013, Iceland: VSN10-041, Norway: 2011/884/REC, and Sweden: Ö 10-2010, 2011/19).

\section{Acknowledgements}

The authors thank Andrea Bautz for tremendous contribution to data management, Klaus Kaae Andersen for statistical advice, and members of the ALiCCS board Catherine Rechnitzer, Kirsi Jahnukainen, and Lars Hjorth for their valuable guidance and discussions. All authors have approved the final manuscript. Trine Gade Bonnesen had full access to all the data in the study and takes the full responsibility for the integrity of the data and the accuracy of the analyses.

\section{Appendix A. Supplementary data}

Supplementary data related to this article can be found at http://dx.doi.org/10.1016/j.ejca.2016.05.006.

\section{References}

[1] Gatta G, Botta L, Rossi S, Aareleid T, Bielska-Lasota M, Clavel J, et al. Childhood cancer survival in Europe 1999-2007: results of EUROCARE-5-a population-based study. Lancet Oncol 2014;15:35-47.

[2] Olsen JH, Moller T, Anderson H, Langmark F, Sankila R, Tryggvadottir L, et al. Lifelong cancer incidence in 47,697 patients treated for childhood cancer in the Nordic countries. J Natl Cancer Inst 2009;101:806-13.

[3] Oeffinger KC, Mertens AC, Sklar CA, Kawashima T, Hudson MM, Meadows AT, et al. Chronic health conditions in adult survivors of childhood cancer. N Engl J Med 2006;355: $1572-82$.

[4] Reulen RC, Winter DL, Lancashire ER, Zeegers MP, Jenney ME, Walters SJ, et al. Health-status of adult survivors of childhood cancer: a large-scale population-based study from the British Childhood Cancer Survivor Study. Int J Cancer 2007;121: 633-40.

[5] Skinner R, Cotterill SJ, Stevens MC. Risk factors for nephrotoxicity after ifosfamide treatment in children: a UKCCSG Late Effects Group study. United Kingdom Children's Cancer Study Group. Br J Cancer 2000;82:1636-45.

[6] Dekkers IA, Blijdorp K, Cransberg K, Pluijm SM, Pieters R, Neggers SJ, et al. Long-term nephrotoxicity in adult survivors of childhood cancer. Clin J Am Soc Nephrol 2013;8: 922-9.

[7] Jones DP, Spunt SL, Green D, Springate JE, Children's Oncology G. Renal late effects in patients treated for cancer in childhood: a report from the Children's Oncology Group. Pediatr Blood Cancer 2008;51:724-31.

[8] Hudson MM, Ness KK, Gurney JG, Mulrooney DA, Chemaitilly W, Krull KR, et al. Clinical ascertainment of health outcomes among adults treated for childhood cancer. JAMA 2013;309:2371-81.

[9] de Fine Licht S, Winther JF, Gudmundsdottir T, Holmqvist AS, Bonnesen TG, Asdahl PH, et al. Hospital contacts for endocrine disorders in Adult Life after Childhood Cancer in Scandinavia (ALiCCS): a population-based cohort study. Lancet 2014;383: 1981-9.

[10] Gudmundsdottir T, Winther JF, de Fine Licht S, Bonnesen TG, Asdahl PH, Tryggvadottir L, et al. Cardiovascular disease in Adult Life after Childhood Cancer in Scandinavia (ALiCCS): a population-based cohort study of 32,308 one-year survivors. Int J Cancer 2015;137:1176-86.

[11] Asdahl PH, Winther JF, Bonnesen TG, De Fine Licht S, Gudmundsdottir T, Anderson H, et al. The Adult Life after Childhood Cancer in Scandinavia (ALiCCS) study: design and characteristics. Pediatr Blood Cancer 2015;62:2204-10.

[12] Gjerstorff ML. The Danish cancer registry. Scand J Public Health 2011;39:42-5.

[13] Teppo L, Pukkala E, Lehtonen M. Data quality and quality control of a population-based cancer registry. Experience in Finland. Acta Oncol 1994:33:365-9.

[14] Larsen IK, Smastuen M, Johannesen TB, Langmark F, Parkin DM, Bray F, et al. Data quality at the Cancer Registry of Norway: an overview of comparability, completeness, validity and timeliness. Eur J Cancer 2009;45:1218-31.

[15] Sigurdardottir LG, Jonasson JG, Stefansdottir S, Jonsdottir A, Olafsdottir GH, Olafsdottir EJ, et al. Data quality at the Icelandic Cancer Registry: comparability, validity, timeliness and completeness. Acta Oncol 2012;51:880-9.

[16] Barlow L, Westergren K, Holmberg L, Talback M. The completeness of the Swedish cancer register: a sample survey for year 1998. Acta Oncol 2009;48:27-33.

[17] Birch JM, Marsden HB. A classification scheme for childhood cancer. Int J Cancer 1987;40:620-4. 
[18] Schmidt M, Pedersen L, Sorensen HT. The Danish civil registration system as a tool in epidemiology. Eur J Epidemiol 2014;29: $541-9$.

[19] Sund R. Quality of the Finnish hospital discharge register: a systematic review. Scand J Public Health 2012;40:505-15.

[20] Ludvigsson JF, Andersson E, Ekbom A, Feychting M, Kim JL, Reuterwall C, et al. External review and validation of the Swedish national inpatient register. BMC Public Health 2011; $11: 450$.

[21] Lynge E, Sandegaard JL, Rebolj M. The Danish national patient register. Scand J Public Health 2011;39:30-3.

[22] Fieller EC. Some problems in interval estimation. J Roy Stat Soc B 1954;16:175-85.

[23] Robison LL, Armstrong GT, Boice JD, Chow EJ, Davies SM, Donaldson SS, et al. The Childhood Cancer Survivor Study: a National Cancer Institute-supported resource for outcome and intervention research. J Clin Oncol 2009;27:2308-18.

[24] Girman CJ, Kou TD, Brodovicz K, Alexander CM, O’Neill EA, Engel S, et al. Risk of acute renal failure in patients with Type 2 diabetes mellitus. Diab Med 2012;29:614-21.

[25] Chittineni H, Miyawaki N, Gulipelli S, Fishbane S. Risk for acute renal failure in patients hospitalized for decompensated congestive heart failure. Am J Nephrol 2007;27:55-62.

[26] Sun WY, Reiser IW, Chou SY. Risk factors for acute renal insufficiency induced by diuretics in patients with congestive heart failure. Am J Kidney Dis 2006;47:798-808.

[27] Sinclair EA, Yenokyan G, McMunn A, Fadrowski JJ, Milstone AM, Lee CK. Factors associated with acute kidney injury in children receiving vancomycin. Ann Pharmacother 2014; 48:1555-62.

[28] Fisher BT, Zaoutis TE, Leckerman KH, Localio R, Aplenc R. Risk factors for renal failure in pediatric patients with acute myeloid leukemia: a retrospective cohort study. Pediatr Blood Cancer 2010;55:655-61.

[29] Knijnenburg SL, Jaspers MW, van der Pal HJ, Schouten-van Meeteren AY, Bouts AH, Lieverst JA, et al. Renal dysfunction and elevated blood pressure in long-term childhood cancer survivors. Clin J Am Soc Nephrol 2012;7:1416-27.
[30] Bardi E, Olah AV, Bartyik K, Endreffy E, Jenei C, Kappelmayer J, et al. Late effects on renal glomerular and tubular function in childhood cancer survivors. Pediatr Blood Cancer 2004:43:668-73.

[31] Christensen AM, Pauley JL, Molinelli AR, Panetta JC, Ward DA, Stewart CF, et al. Resumption of high-dose methotrexate after acute kidney injury and glucarpidase use in pediatric oncology patients. Cancer 2012;118:4321-30.

[32] Armstrong GT, Kawashima T, Leisenring W, Stratton K, Stovall M, Hudson MM, et al. Aging and risk of severe, disabling, life-threatening, and fatal events in the childhood cancer survivor study. J Clin Oncol 2014;32:1218-27.

[33] Loebstein R, Atanackovic G, Bishai R, Wolpin J, Khattak S, Hashemi G, et al. Risk factors for long-term outcome of ifosfamide-induced nephrotoxicity in children. J Clin Pharmacol 1999; 39:454-61.

[34] Rossi R, Pleyer J, Schafers P, Kuhn N, Kleta R, Deufel T, et al. Development of ifosfamide-induced nephrotoxicity: prospective follow-up in 75 patients. Med Pediatr Oncol 1999;32:177-82.

[35] Skinner R, Parry A, Price L, Cole M, Craft AW, Pearson AD Glomerular toxicity persists 10 years after ifosfamide treatment in childhood and is not predictable by age or dose. Pediatr Blood Cancer 2010;54:983-9.

[36] Rossi R, Godde A, Kleinebrand A, Riepenhausen M, Boos J, Ritter J, et al. Unilateral nephrectomy and cisplatin as risk factors of ifosfamide-induced nephrotoxicity: analysis of 120 patients. J Clin Oncol 1994;12:159-65.

[37] Frandsen TL, Heyman M, Abrahamsson J, Vettenranta K, Asberg A, Vaitkeviciene G, et al. Complying with the European Clinical Trials directive while surviving the administrative pressure-an alternative approach to toxicity registration in a cancer trial. Eur J Cancer 2014;50:251-9.

[38] Howard SC, Kaplan SD, Razzouk BI, Rivera GK, Sandlund JT, Ribeiro RC, et al. Urolithiasis in pediatric patients with acute lymphoblastic leukemia. Leukemia 2003;17:541-6.

[39] Hoffmeister PA, Storer BE, Baker KS, Hingorani SR. Nephrolithiasis in pediatric hematopoietic cell transplantation with up to 40 years of follow-up. Pediatr Blood Cancer 2014;61:417-23. 